\title{
Analisis Pengaruh Ekuitas Merek PT Pos Indonesia (Persero) KPC Jakarta Pusat Dalam Menarik Konsumen
}

\author{
Syamruddin ${ }^{*}$, Euis Tatu Aisyah ${ }^{2}$ \\ 1Fakultas Ekonomi, Universitas Pamulang; dosen01343@unpam.ac.id* \\ 2Fakultas Ekonomi Universitas Pamulang; aisyahdecha108@gmail.com
}

\begin{abstract}
Abstrak
Tujuan penelitian ini untuk mengetahui pengaruh ekuitas merek PT Pos Indonesia (Persero) KPC Jakarta Pusat dalam menarik konsumen melalui keputusan pembelian. Penelitian menggunakan metode deskriptif kuantitaif. Adapun teknik analisis data yang digunakan dalam penelitian ini yaitu Analisis Regresi Linier Sederhana, Analisis Koefisien Korelasi, Analisis Koefisien Determinasi, dan Pengujian Hipotesis (Uji t). Adapun hasil penelitian menunjukkan adanya faktor yang kuat pada ekuitas merek dalam menarik konsumen untuk menggunakan produk yang ditawarkan oleh perusahaan. Hal itu ditunjukkan pada hasil pengujian di mana Ekuitas Merek berpengaruh sebesar 59,8\% terhadap Keputusan Pembelian. Sisanya sebesar 40,2\% dipengaruhi oleh faktor-faktor lain. Sedangkan dalam uji hipotesis diperoleh nilai $t$ hitung $>t$ tabel atau (12,004 > 1.985), sehingga $H_{O}$ ditolak dan $H_{1}$ diterima.
\end{abstract}

Kata Kunci : Ekuitas Merek; Keputusan Pembelian; Konsumen

\begin{abstract}
Abstrack
The purpose of this study was to determine the effect of brand equity of PT Pos Indonesia (Persero) KPC Central Jakarta in attracting consumers through purchasing decisions. This research used a quantitative descriptive method. The data analysis techniques used in this study are Simple Linear Regression Analysis, Correlation Coefficient Analysis, Determination Coefficient Analysis, and Hypothesis Testing ( $t$ test). The results of this study indicate a strong factor in brand equity in attracting consumers to use the products offered by the company. This is shown in the test results where Brand Equity has an effect of 59,8\% on Purchasing Decisions. The remaining 40,2\% is influenced by other factors. While in the hypothesis test, the value of $t$ count $>t$ table or $(12.004>1.985)$ is obtained, so that $H_{o}$ is rejected and $H_{1}$ is accepted.
\end{abstract}

Keywords : Brand Equity; Purchasing Decision; Consumer

\footnotetext{
$\left.{ }^{*}\right)$ Korespondensi penulis
} 


\section{PENDAHULUAN}

Persaingan bisnis jasa pos atau pengiriman barang dewasa ini semakin ketat. Pelaku bisnis di pasar jasa ini sangat banyak. Tak hanya pemain besar, namun juga skala kecil banyak tumbuh, apalagi di tengah Pandemi COVID-19 sekarang ini. Bak jamur di musim hujan, pelaku bisnis jasa pengiriman barang tumbuh dan berkembang seiring dengan banyaknya permintaan masyarakat terhadap layanan pada bisnis ini.

Salah satu perusahaan yang sudah sangat eksis dalam bisnis jasa pos atau pengiriman barang yakni PT Pos Indonesia (Persero). Badan Usaha Milik Negara (BUMN) ini telah berdiri 276 tahun silam atau tepatnya pada 26 Agustus 1746. Perusahaan pelat merah ini semakin memperkokoh pondasinya dan terus mengembangkan sayapnya di bisnis jasa pos.

Seiring dengan perkembangan bisnis, Pos Indonesia pun terus bertransformasi. Di antaranya menjadi layanan pengiriman terpercaya serta menjadi kekuatan logistik dan e-commerce Indonesia. Selain itu mendukung kemudahan akses finansial dan menjadi inovator digital. Transformasi Pos Indonesia ini semuanya diwujudkan dalam berbagai produk pos.

Selanjutnya, salah satu yang juga menjadi bagian penting dilakukan perusahaan yang memiliki motto "Tepat waktu setiap waktu" ini, yaitu strategi penguatan ekuitas merek (brand equity). Melalui srategi ini Pos Indonesia diharapkan menjadi leader di sektornya. Hal ini sesuai dengan visi Pos Indonesia yaitu menjadi pilihan utama layanan logistik dan jasa keuangan.

Menurut Kotler \& Keller (2017:263), ekuitas merek adalah nilai tambah yang diberikan pada produk dan jasa. Ekuitas merek dapat tercermin dalam cara konsumen berpikir, merasa, dan bertindak dalam hubungan dengan merek. Selain itu juga terhadap harga, pangsa pasar, dan profitabilitas yang diberikan merek bagi perusahaan.

Sementara itu menurut Aaker (2014:8), ekuitas merek merupakan seperangkat aset dan liabilitas merek yang berkaitan dengan suatu merek, nama dan simbolnya, yang menambah atau mengurangi nilai yang diberikan oleh suatu barang atau jasa kepada perusahaan atau pelanggan perusahaan. Sedangkan menurut Supranto dan Limakrisna (2011:132), ekuitas merek adalah nilai yang ditentukan oleh konsumen pada suatu merek di atas dan di luar karakteristik/ atribut fungsional dari produk.

Selanjutnya dalam penelitian sebelumnya diperoleh hasil bawah ekuitas merek merupakan salah satu strategi yang sangat penting dalam membangun perusahaan. Penguatan ekuitas merek diharapkan dapat menarik konsumen dalam memutuskan pembelian terhadap produk-produk yang ditawarkan. Sehingga strategi memperkuat merek merupakan salah satu yang cukup ampuh dilakukan oleh perusahaan dewasa ini.

Berdasarkan penelitian terdahulu yang dilakukan oleh I Gede Teguh Esa Widhiarta dan I Made Wardana, yang berjudul: Pengaruh Ekuitas Merek Terhadap Keputusan Pembelian Iphone di Denpasar. Adapun penelitian dilakukan pada 2014. Hasil penelitian menunjukkan bahwa dengan penguatan ekuitas merek akan mempengaruhi konsumen dalam memutuskan pembelian.

Dalam penelitian terdahulu yang dilakukan oleh Raditya Pratama Putra, Neni Yulianita, Yusuf Hamdan, dan Anne Ratnasari yang berjudul: Analisis Brand Equity Perusahaan Melalui Media Sosial (Studi Kasus Pada Bagian Media Komunikasi PT. Pos Indonesia Persero). Penelitian dilakukan pada 2016. Berdasarkan penelitian diperoleh kesimpulan bahwa penggunaan media sosial sangat berperan dalam membangun 
ekuitas merek. Dengan terbangunnya ekuitas merek yang kuat akan berdampak pada keputusan konsumen dalam memutuskan pembelian.

Sedangkan dalam penelitian terdahulu lainnya yang dilakukan oleh Marco Dirgahadi Lukman dengan judul: Analisis Pengaruh Ekuitas Merek Terhadap Keputusan Pembelian dan Kepuasan Konsumen Produk Teh Botol Sosro Kemasan Kotak. Penelitian dilakukan pada 2012. Dari penelitian tersebut dapat diketahui adanya pengaruh ekuitas merek Teh Botol Sosro yang terdiri dari brand awareness dan brand image terhadap keputusan pembelian dan kepuasan konsumen cukup baik.

Oleh karena itu berdasarkan hal-hal di atas, maka penulis tertarik untuk menulis hasil penelitian dengan judul : "Analisis Pengaruh Ekuitas Merek PT Pos Indonesia (Persero) KPC Jakarta Pusat Dalam Menarik Konsumen.”

\section{METODE}

Adapun metode yang digunakan dalam penelitian ini yaitu deskriptif kuantitaif. Menurut Sugiyono (2017:8), penelitian kuantitatif merupakan metode penelitian yang berlandaskan pada filsafat positivisme, digunakan untuk meneliti pada populasi atau sampel tertentu, pengumpulan data menggunakan instrumen penelitian, analisis data bersifat kuantutatif atau statistik, dan dengan tujuan untuk menguji hipotesis yang telah ditetapkan.

Selanjutnya Sugiyono (2017:147), berpendapat bahwa dalam penelitian kuantitatif, analisis data merupakan kegiatan pengumpulan data dari sumbersumber yang diperoleh. Adapun kegiatan dalam analisis data yakni mengelompokkan data berdasarkan variabel dan jenisnya, mentabulasi berdasarkan variabel, menyajikan data berdasarkan variabel yang diteliti, melakukan perhitungan untuk menjawab rumusan masalah, dan melakukan perhitungan untuk menguji hipotesis yang telah diajukan.

Kemudian teknik analisis data yang digunakan dalam penelitian ini yaitu Analisis Regresi Linier Sederhana, Analisis Koefisien Korelasi, Analisis Koefisien Determinasi, dan Pengujian Hipotesis (Uji t). Teknik analisis data ini akan memberikan gambaran bagaimana penguatan ekuitas merek merupakan salah satu strategi yang cukup berhasil dalam menarik konsumen untuk menggunakan produk yang ditawarkan oleh perusahaan. Melalui teknik analisis data yang dipaparkan pada bab berikutnya akan menunjukkan adanya pengaruh yang kuat antara ekuitas merek dalam menarik konsumen melalui keputusan pembelian.

\section{HASIL dan PEMBAHASAN Hasil}

Analisis deskriptif kuantitatif dimaksudkan untuk mengetahui besarnya pengaruh dan menganalisis signifikansinya. Analisis dilakukan terhadap pengaruh ekuitas merek dalam menarik konsumen melalui keputusan pembelian. Sehingga salah satu strategi PT Pos Indonesia (Persero) KPC Jakarta Pusat dalam menarik konsumen yakni melalui ekuitas merek dianggap sangat tepat. Adapun analisis yang dipaparkan yaitu Analisis Regresi Linier Sederhana, Analisis Koefisien Korelasi, Analisis Koefisien Determinasi, dan Pengujian Hipotesis (Uji t).

\section{Analisis Regresi Linier Sederhana}

Uji regresi ini dimaksudkan untuk mengetahui perubahan pada variabel dependen jika variabel independen mengalami perubahan. Dalam penelitian ini yakni antara Ekuitas Merek (X) terhadap Keputusan Pembelian (Y) pada PT. Pos Indonesia (Persero) KPC Jakarta Pusat. Hasil olah data dengan teknik 
Regresi Linier Sederhana menggunakan SPSS Versi 26 dapat dilihat pada Tabel 1.

\section{Tabel 1. Hasil Pengolahan} Regresi Linier Sederhana Coefficients ${ }^{a}$

\begin{tabular}{|c|c|c|c|c|c|c|}
\hline \multicolumn{2}{|c|}{ Model } & \multicolumn{2}{|c|}{$\begin{array}{l}\text { Unstandardized } \\
\text { Coefficients }\end{array}$} & $\begin{array}{c}\text { Standardized } \\
\text { Coefficients } \\
\text { Beta }\end{array}$ & $\mathrm{t}$ & Sig. \\
\hline \multirow[t]{2}{*}{1} & (Constant) & 14.154 & 3.625 & & 3.905 & .000 \\
\hline & $\begin{array}{l}\text { Ekuitas } \\
\text { Merek (X) }\end{array}$ & 1.268 & .106 & .773 & 12.004 & .000 \\
\hline
\end{tabular}

Sumber: Data Primer (Diolah, 2020)

Berdasarkan tabel di atas, diperoleh persamaan Regresi Linier Sederhana yaitu $: \mathrm{Y}=14,154+1,268 \mathrm{X}$. Dengan demikian adapat dijelaskan bahwa nilai konstanta sebesar 14,154 diartikan bahwa jika variabel Ekuitas Merek tidak ada maka telah terdapat Keputusan Pembelian sebesar 14,154. Kemudian nilai coefisien betta 1,268 diartikan apabila konstanta tetap dan tidak ada perubahan pada variabel lain, maka setiap perubahan 1 satuan pada variabel Ekuitas Merek, maka akan mengakibatkan terjadinya perubahan pada Keputusan Pembelian sebesar 1,268 poin.

\section{Analisis Koefisien Korelasi}

Analisis Koefisien Korelasi digunakan untuk mengetahui tingkat kekuatan hubungan atau pengaruh antara variabel Ekuitas Merek terhadap Keputusan Pembelian pada PT. Pos Indonesia (Persero) KPC Jakarta Pusat. Adapun hasil pengolahan data dengan menggunakan program SPSS Versi 26, seperti tampak pada Tabel 2.

\begin{tabular}{|c|c|c|c|}
\hline \multicolumn{4}{|c|}{$\begin{array}{l}\text { Tabel 2. Hasil Analisis } \\
\text { Koefisien Korelasi } \\
\text { Correlations }^{b}\end{array}$} \\
\hline & & $\begin{array}{c}\text { Ekuitas } \\
\text { Merek (X) }\end{array}$ & $\begin{array}{c}\text { Keputusan } \\
\text { Pembelian (Y) }\end{array}$ \\
\hline \multirow[t]{2}{*}{$\begin{array}{l}\text { Ekuitas } \\
\text { Merek (X) }\end{array}$} & \begin{tabular}{|l} 
Pearson \\
Correlation
\end{tabular} & 1 & $.773^{* *}$ \\
\hline & Sig. (2-tailed) & & .000 \\
\hline \multirow{2}{*}{$\begin{array}{l}\text { Keputusan } \\
\text { Pembelian } \\
\text { (Y) }\end{array}$} & $\begin{array}{l}\text { Pearson } \\
\text { Correlation }\end{array}$ & $.773^{* * *}$ & 1 \\
\hline & \begin{tabular}{|l} 
Sig. (2-tailed) \\
\end{tabular} & .000 & \\
\hline
\end{tabular}

Sumber: Data Primer (Diolah, 2020)

Berdasarkan tabel di atas, diperoleh nilai Koefisien Korelasi (R) sebesar 0,773, di mana nilai tersebut berada pada interval
0,600-0,799 artinya Ekuitas Merek (X) memiliki tingkat hubungan yang kuat terhadap Keputusan Pembelian (Y).

\section{Analisis Koefisien Determinasi}

Analisis Koefisien Determinasi dipergunakan untuk mengukur besarnya pengaruh variabel independen terhadap dependen. Berikut ini hasil perhitungan koefisien determinasi yang diolah dengan menggunakan program SPSS Versi 26, sebagaimana ditunjukkan pada Tabel 3.

\section{Tabel 3. Hasil Analisis \\ Koefisien Determinasi Model Summary}

\begin{tabular}{|l|c|c|c|c|} 
Model & $\mathrm{R}$ & $\begin{array}{c}\mathrm{R} \\
\text { Square }\end{array}$ & $\begin{array}{c}\text { Adjusted R } \\
\text { Square }\end{array}$ & $\begin{array}{c}\text { Std. Error of } \\
\text { the Estimate }\end{array}$ \\
\hline 1 & $.773^{\mathrm{a}}$ & .598 & .594 & 4.040 \\
\hline
\end{tabular}

Sumber: Data Primer (Diolah, 2020)

Berdasarkan hasil uji pada tabel di atas, diperoleh nilai $R$-square (Koefisien Determinasi) sebesar 0,598. Dengan demikian, maka dapat disimpulkan bahwa Ekuitas Merek (X) berpengaruh terhadap Keputusan Pembelian (Y) sebesar 59,8\%. Adapun sisanya sebesar $(100-59,8 \%)=$ 40,2\% dipengaruhi oleh faktor lain.

\section{Pengujian Hipotesis (Uji t)}

Pengujian hipotesis dimaksudkan untuk menguji penerimaan dan penolakan dari rumusan hipotesis. Adapun rumusan hipotesis dalam penelitian ini sebagai berikut:

$\mathrm{H}_{\mathrm{o}}: \rho=\mathrm{o}$ Tidak terdapat pengaruh antara Ekuitas Merek terhadap Keputusan Pembelian pada PT. Pos Indonesia (Persero) KPC Jakarta Pusat.

$\mathrm{H}_{1}: \rho \neq \mathrm{O}$ Terdapat pengaruh antara Ekuitas Merek terhadap Keputusan Pembelian pada PT. Pos Indonesia (Persero) KPC Jakarta Pusat.

Dalam penelitian ini digunakan kriteria signifikansi $5 \%(0,05)$ dengan membandingkan $\mathrm{t}$ hitung dengan $\mathrm{t}$ tabel yaitu sebagai berikut: 
a. Jika $\mathrm{t}$ hitung $<\mathrm{t}_{\text {tabel: }}$ berarti $\mathrm{H}_{\mathrm{o}}$ diterima dan $\mathrm{H}_{1}$ ditolak

b. Jika $\mathrm{t}_{\text {hitung }}>\mathrm{t}_{\text {tabel: }}$ : berarti $\mathrm{H}_{\mathrm{o}}$ ditolak dan $\mathrm{H}_{1}$ diterima

Besarnya $t_{\text {tabel }}$ dicari dengan menggunakan rumus:

$\mathrm{df}=(\mathrm{n}-2$, maka diperoleh $(99-2)=97$ sehingga $t_{\text {tabel }}=1.985$

Kriteria dikatakan signifikan jika nilai $\mathrm{t}$ hitung $>\mathrm{t}$ tabel atau probability signifikansi $<0,05$. Selanjutnya hasil pengolahan data dengan program menggunakan SPSS Versi 26, seperti halnya pada Tabel 4.

Tabel 4. Hasil Uji Hipotesis (Uji t) Coefficients ${ }^{a}$

\begin{tabular}{|l|l|r|r|r|r|r|}
\hline \multirow{2}{*}{ Model } & \multicolumn{2}{|c|}{$\begin{array}{c}\text { Unstandardized } \\
\text { Coefficients }\end{array}$} & $\begin{array}{c}\text { Standardized } \\
\text { Coefficients }\end{array}$ & \multirow{2}{*}{ Sig. } & \\
\hline \multirow{2}{*}{1} & B & \multicolumn{1}{c|}{$\begin{array}{c}\text { Std. } \\
\text { Error }\end{array}$} & Beta & & \\
\cline { 2 - 7 } & (Constant) & 14.154 & 3.625 & & 3.905 & .000 \\
\hline & $\begin{array}{l}\text { Ekuitas } \\
\text { Merek (X) }\end{array}$ & 1.268 & .106 & .773 & 12.004 & .000 \\
\hline
\end{tabular}

Sumber: Data Primer (Diolah, 2020)

Berdasarkan tabel di atas diperoleh nilai $t_{\text {hitung }}>t_{\text {tabel }}$ atau (12.004 $\left.>1.985\right)$. Hal itu juga diperkuat dengan signifikansi o,00o < 0,05. Dengan demikian maka $\mathrm{H}_{\mathrm{o}}$ ditolak dan $\mathrm{H}_{1}$ diterima, $\mathrm{Hal}$ ini menunjukkan bahwa terdapat pengaruh positif dan signifikan antara Ekuitas Merek terhadap Keputusan Pembelian pada PT. Pos Indonesia (Persero) KPC Jakarta Pusat.

\section{Pembahasan}

Ekuitas Merek berpengaruh signifikan dalam menarik konsumen melalui Keputusan Pembelian dengan persamaan regresi linier $\mathrm{Y}=14,154+$ 1,268X. Konstanta bernilai positif dengan tingkat hubungan (korelasi) sebesar 0,773 atau kuat dengan kontribusi pengaruhnya (determinasi) sebesar 0,598 atau 59,8\%. Sedangkan sisanya sebesar 40,2\% dipengaruhi oleh faktor lain.

Adapun berdasarkan uji hipotesis diperoleh nilai $\mathrm{t}$ hitung $>\mathrm{t}$ tabel atau $(12,004>1,985)$. Hal itu juga dibuktikan dengan signifikansi 0,00o < 0,05. Dengan demikian, maka $\mathrm{H}_{\mathrm{o}}$ ditolak dan $\mathrm{H}_{1}$ diterima. Hal ini menunjukkan bahwa terdapat pengaruh signifikan antara Ekuitas Merek dalam menarik konsumen melalui Keputusan Pembelian pada PT. Pos Indonesia (Persero) KPC Jakarta Pusat.

\section{SIMPULAN}

Pengaruh ekuitas merek PT Pos Indonesia (Persero) KPC Jakarta Pusat dalam menarik konsumen melalui keputusan pembelian sangat kuat. Hal itu dapat dibuktikan dengan adanya pengaruh yang kuat antara Ekuitas Merek terhadap Keputusan Pembelian. Ada korelasi yang kuat di mana Ekuitas Merek berpengaruh sebesar 59,8\% terhadap Keputusan Pembelian. Sisanya sebesar 40,2\% dipengaruhi oleh faktor-faktor lain. Sedangkan dalam uji hipotesis diperoleh nilai $\mathrm{t}$ hitung $>\mathrm{t}$ tabel atau (12,004 > 1,985). Dengan demikian, maka $\mathrm{H}_{\mathrm{o}}$ ditolak dan $\mathrm{H}_{1}$ diterima.

\section{UCAPAN TERIMA KASIH}

Ucapan terima kasih disampaikan kepada manajemen PT Pos Indonesia (Persero) KPC Jakarta Pusat yang telah memberikan kesempatan kepada penulis untuk melakukan penelitian. Mudahmudahan hasil penelitian ini dapat bermanfaat bagi perusahaan, penulis, dan para pembaca.

\section{DAFTAR PUSTAKA}

Aaker, David A. (2014). Managing Brand Equity: Capitalizing on the Value of a Brand Name. New York. The Free Press.

Algustin, W., \& Matoati, R. (2020). Pengaruh Ekuitas Merek terhadap Minat Beli Ulang Produk Emina Pada Generasi Z. Jurnal Bisnis dan Ekonomi, 27(1).

Aprilia, Y. D., \& Verinita, V. (2019). Pengaruh Ekuitas Merek Terhadap Keputusan Menabung Nasabah 
Tabungan Ebatara Pos di Kantor Layanan Setara Kantor Kas (KLKK) Pariaman. Jurnal Ilmiah Mahasiswa Ekonomi Manajemen, 4(3), 519-532. Ariyanto, Y. (2016). Pengaruh Ekuitas Merek Dan Gaya Hidup Terhadap Keputusan Pembelian Mobil Nissan Juke. Jurnal Ilmu dan Riset Manajemen (JIRM), 5(3).

Fibriany, F. W., \& Dewi, Y. N. (2020). Analisis Ekuitas Merek Kedai Kopi Kekinian. Journal of Marketing Modern, 1(2), 63-71.

Khasanah, I. (2013). Analisis Pengaruh Ekuitas Merek Terhadap Keputusan Pembelian Mie Instan Sedaap di Semarang. JDM (Jurnal Dinamika Manajemen), 4(1).

Kirana, E. K. (2019). Pengaruh Ekuitas Merek dan Kepercayaan Konsumen Terhadap Keputusan Penggunaan Jasa Ekspedisi (Studi Pada Konsumen Jalur Nugraha Ekakurir). Manajemen Bisnis, 8(1).

Kotler, Philip \& Keller. (2017). Manajemen Pemasaran. Terjemahan Bob Sabran. Edisi ke 13. Jilid 1. Jakarta: Erlangga.

Lukman, M. D. (2014). Analisis Pengaruh Ekuitas Merek Terhadap Keputusan Pembelian dan Kepuasan Konsumen Produk Teh Botol Sosro Kemasan Kotak. Jurnal Administrasi Bisnis, $10(1)$.

Murhadi, T. (2019). Pengaruh Ekuitas Merek terhadap Keputusan Pembelian LintasartaNet di Kota Banda Aceh. Jurnal Ilman: Jurnal Ilmu Manajemen, 7(1).

Mustofa, B., \& Sutopo, S. (2013). Analisis Pengaruh Ekuitas Merek Terhadap Keputusan Pembelian Sepeda Motor Merek Yamaha (studi kasus pada Mahasiswa Universitas Diponegoro).

Diponegoro Journal of Management, 10-20.

Nurfitriani, A., \& Suhartini, T. (2018). Strategi Marketing Public Relations
PT. Pos Indonesia. $J-I K A, 5(1), 66-$ 70.

Putra, R. P., Yulianita, N., Hamdan, Y., \& Ratnasari, A. (2018). Analisis Brand Equity Perusahaan Melalui Media Sosial (Studi Kasus pada Bagian Media Komunikasi PT. Pos Indonesia Persero). Idea: Jurnal Humaniora, 50-62.

Pinassang, A. W., \& Rahardjo, S. T. (2017). Pengaruh Ekuitas Merek Terhadap Keputusan Pembelian Laptop Merek Toshiba Di Semarang. Diponegoro Journal of Management, 6(4), 123134.

Putri, V. D. A., \& Suasana, I. G. A. K. G. (2017). Pengaruh elemen ekuitas merek terhadap keputusan pembelian di gerai Starbucks coffee (Studi pada konsumen domestik Starbucks coffee di wilayah Bali). EJurnal Manajemen, 7(1), 470-496.

Rido, F., Fathor, A. S., \& Purnamawati, P. (2019). Pengaruh Ekuitas Merek Terhadap Keputusan Memilih Dengan Minat Sebagai Variabel Intervening. Competence: Journal of Management Studies, 13(1), 44-55.

Sabar, D. R., Mananeke, L., \& Lumanauw, B. (2020). Pengaruh Ekuitas Merek, Atribut Produk dan Direct Marketing Terhadap Keputusan Pembelian Mobil Toyota Pada PT Hasjrat Abadi Manado Tendean. Jurnal EMBA: Jurnal Riset Ekonomi, Manajemen, Bisnis dan Akuntansi, 8(1).

Suharyani, K., Nuridja, I. M., \& Haris, I. A. (2016). Pengaruh Ekuitas Merek Terhadap Keputusan Pembelian Produk Minuman Teh Botol Sosro Pada Mahasiswa Jurusan Pendidikan Ekonomi Undiksha 2015. Jurnal Pendidikan Ekonomi Undiksha, 5(1). Sugiyono. (2017). Metode Penelitian Kuantitatif, Kualitatif, dan $R \& D$. Bandung: CV Alfabeta.

Supranto dan Limakrisna, Nandan. (2011). Perilaku Konsumen dan Strategi 
Pemasaran. Edisi Kedua. Jakarta: Mitra Wacana Media.

Syamruddin, S., \& Hakim, F. N. (2019). Pengaruh Ekuitas Merek Terhadap Keputusan Pembelian Handphone Xiaomi. Jurnal Madani: Ilmu Pengetahuan, Teknologi, dan Humaniora, 2(1), 147-161.

Taqwa, D. M. (2020). Analisis Ekuitas Merek Komunikasi Pemasaran Terpadu Pada Moda Ojek Online "Grab". Jurnal Ekonomi, Sosial \& Humaniora, 1(08), 20-27.

Wiastuti, R. D., \& Kimberlee, S. (2018). Pengaruh Ekuitas Merek Terhadap Keputusan Pembelian di Simetri Coffee Roaster Puri, Jakarta. Jurnal Pariwisata, 5(2), 133-146.

Widhiarta, I. G. T. E., \& Wardana, M. (2015). Pengaruh Ekuitas Merek terhadap Keputusan Pembelian Iphone di Denpasar. E-Jurnal Manajemen Universitas Udayana, 4(4).

William, C., \& Japarianto, E. (2014). Analisis Pengaruh Ekuitas Merek Terhadap Minat Beli Konsumen Ice Cream Di De Boliva Surabaya. Jurnal Hospitality dan Manajemen Jasa, 2(2), 1-15.

Yusuf, A., \& Sudrajat, A. (2017). Analisis Ekuitas Merek Destinasi Wisata Berdasarkan Perspektif Wisatawan: Kasus pada Pantai-Pantai di Karawang, Jawa Barat. Value: Journal of Management and Business, 2(1).

Yuvita, H., Wahab, Z., \& Sulastri, S. (2019). Pengaruh Brand Image dan Sales Promotion Terhadap Keputusan Pembelian Melalui Brand Equity (Survei Terhadap Nasabah Bank Bni Syariah Di Kota Palembang). MIX: Jurnal Ilmiah Manajemen, 9(3), 293235.

https://www.tribunnewswiki.com/2019/1 o/25/pt-pos-indonesia-persero. 